\title{
Editorial: Coral Reefs in the Anthropocene - Reflecting on 20 Years of Reef Conservation UK
}

\begin{abstract}
Dominic A. Andradi-Brown ${ }^{1 *}$, Anastazia T. Banaszak², Thomas K. Frazer ${ }^{3}$, Hannah Gilchrist ${ }^{4}$, Alastair R. Harborne ${ }^{5}$, Catherine E. I. Head ${ }^{6,7}$, Heather J. Koldewey ${ }^{8,9}$, Emma Levy ${ }^{8}$, Kirsty Richards ${ }^{10}$, Rebecca Short ${ }^{11}$, Michael Sweet ${ }^{12}$, Kristian Teleki ${ }^{13,14}$, Christian R. Voolstra ${ }^{15}$, Bryan Wilson ${ }^{7}$, Elizabeth Wood ${ }^{16}$, Robert T. Yarlett ${ }^{17}$ and David J. Curnick ${ }^{6}$

${ }^{1}$ Ocean Conservation, World Wildlife Fund, Washington, DC, United States, ${ }^{2}$ Unidad Académica de Sistemas Arrecifales, Universidad Nacional Autónoma de México, Puerto Morelos, Mexico, ${ }^{3}$ School of Natural Resources and Environment, University of Florida, Gainesville, FL, United States, ${ }^{4}$ Blue Ventures, Bristol, United Kingdom, ${ }^{5}$ Department of Biological Sciences, Florida International University, North Miami, FL, United States, ${ }^{6}$ Institute of Zoology, Zoological Society of London, London, United Kingdom, ${ }^{7}$ Department of Zoology, University of Oxford, Oxford, United Kingdom, ${ }^{8}$ Conservation \& Policy, Zoological Society of London, London, United Kingdom, ${ }^{9}$ Centre for Ecology and Conservation, University of Exeter, Penryn, United Kingdom, ${ }^{10}$ Atmosphere Resorts, Dauin, Philippines, ${ }^{11}$ European Centre for Environment and Human Health, University of Exeter Medical School, Royal Cornwall Hospital, Truro, United Kingdom, ${ }^{12}$ Aquatic Research Facility, Environmental Sustainability Research Centre, University of Derby, Derby, United Kingdom, ${ }^{13}$ Sustainable Ocean Initiative, World Resources Institute, London, United Kingdom, ${ }^{14}$ Friends of Ocean Action, World Economic Forum, Geneva, Switzerland, ${ }^{15}$ Department of Biology, University of Konstanz, Konstanz, Germany, ${ }^{16}$ Freelance Consultant, Hook, United Kingdom, ${ }^{17}$ Independent Researcher, London, United Kingdom
\end{abstract}

Keywords: coral reef, reef conservation, United Kingdom, RCUK, trends, anthropocene

OPEN ACCESS

Edited and reviewed by:

Eric Jeremy Hochberg,

Bermuda Institute of Ocean

Sciences, Bermuda

*Correspondence:

Dominic A. Andradi-Brown

dominic.andradi-brown@wwfus.org

Specialty section:

This article was submitted to

Coral Reef Research,

a section of the journal

Frontiers in Marine Science

Received: 19 February 2020 Accepted: 29 April 2020

Published: 12 June 2020

Citation: Andradi-Brown DA, Banaszak AT,

Frazer TK, Gilchrist H, Harborne AR, Head CEl, Koldewey HJ, Levy E, Richards $K$, Short R, Sweet M, Teleki K, Voolstra CR, Wilson B, Wood E, Yarlett RT and Curnick DJ (2020) Editorial: Coral Reefs in the Anthropocene - Reflecting on 20 Years of Reef Conservation UK.

Front. Mar. Sci. 7:364.

doi: 10.3389/fmars.2020.00364

\section{Editorial on the Research Topic}

Coral Reefs in the Anthropocene - Reflecting on 20 Years of Reef Conservation UK

\section{INTRODUCTION}

The term "Anthropocene" has been suggested as the current epoch (denoting the current geological age) and is viewed as the period where human-based activity is the dominant influence on climate and the environment (Lewis and Maslin, 2015). Arguably, one of the most prevalent and visible effects of this anthropogenic activity has manifested in the equatorial tropics-where coral reef ecosystems have suffered alarming declines (Pandolfi et al., 2003; Hughes et al., 2017). For example, recent increases in mass bleaching events brought about by prolonged periods of elevated sea surface temperatures highlight a worrying trend, with predictions that over half of reefs will experience annual severe bleaching before 2050 (van Hooidonk et al., 2016). For this reason, coral reefs have often been referred to as "canaries in the coal mine" for the marine biome. Yet reefs continue to be crucial sources of food, protection, livelihoods, and cultural identity for many people around the world (Teh et al., 2013; Hicks and Cinner, 2014; Lau et al., 2019). It is therefore critical that the link between healthy reefs, food security, and sustainable community livelihoods is maintained into the future.

This Research Topic represents the proceedings for the European Coral Reef Symposium (ECRS), which took place 13th-15th December, 2017 in Oxford, UK. ECRS was organised by the Reef Conservation United Kingdom (RCUK) committee, in association with the Zoological Society of London (ZSL), University of Oxford, and the International Coral Reef Society (ICRS). Over 550 coral reef scientists and conservationists joined the meeting for a series of talks, posters, and workshops. In addition to the papers in this Research Topic, ECRS provided a platform for many other coral reef-related events and outputs. For example, the symposium hosted the European 
launch of the 2018 International Year of the Reef on the 13th December 2017, and several of the workshops produced published outputs (e.g., Turner et al., 2019).

In this editorial, we provide a brief history of RCUKcharting the course from inception in 1997 through to ECRS in 2017-including our sustainable conferencing efforts and commitments to diversity and inclusion. We strongly believe that all conferences should carefully consider sustainability, diversity, and inclusion and we hope our efforts will inspire and encourage other conference organisers to do the same. We then introduce the globally relevant coral reef science and conservation that has been presented at RCUK meetings and provide an overview of the papers submitted to this Research Topic. We close by highlighting our vision for RCUK into the future-and lay out how this can be applied to the upcoming Frontiers Spotlight Conference on Coral Reefs.

\section{HISTORY OF RCUK}

RCUK is an informal network for coral reef scientists, students, practitioners, educators, conservationists, aquarists, and policy makers. Though RCUK is UK-based, it is open to all, regardless of location. RCUK formed in response to the first International Year of the Reef (IYOR) in 1997. During that year, UK-based individuals and organisations came together to raise awareness about coral reefs, including a press event, networking meetings, development of communication materials, and education workshops. These activities brought together groups that had not previously communicated-leading to new collaborations and improved information exchange and networking, especially within the UK coral reef community. The original IYOR UK committee felt a conference would be a good way to build on this network for coral reef science and conservation in the UK but did not have the resources to deliver that in 1997. This led to the formation of the first RCUK coordinating committee, followed soon after by the first RCUK conference in 1998. The conference programme for the newlyformed RCUK stated: "We hope that this is the beginning of a sustained and continued effort to ensure that the RCUK and the $U K$ reef community maintain an active role in promoting conservation, public awareness and education about coral reefs, as well as ensuring that all reef-related activities are conducted in a responsible manner" (RCUK, 1998).

Over 20 years later, with a conference held every year since, RCUK is firmly established as a major conference to attend for all things reef-based-and has become a cornerstone of the UK coral reef science and conservation community. RCUK meetings have more than doubled in size, from 100 delegates in the late 1990s (Teleki et al., 2001), to approximately 130 delegates in 2014 and 2015 (Andradi-Brown, 2015; AndradiBrown et al., 2016a), and sell-out meetings with over 200 delegates (the ZSL venue capacity) in 2016 and 2018. In 2017, RCUK coordinated ECRS in Oxford, UK, with over 550 delegates attending. ECRS is a European coral reef conference initiated by ICRS, typically held every 4 years in a different European location. ECRS represents the European regional meeting counterpart to the ICRS-coordinated global International Coral Reef Symposium. Hosting ECRS marked the 20th annual conference of RCUK, and this Research Topic-representing ECRS conference proceedings-marks the important legacy of RCUK to the UK-based coral reef community.

RCUK meetings strive to be friendly conferences, welcome to anyone with an interest in reef studies or conservation regardless of background or career stage, and include an informal evening social event to encourage networking. RCUK meetings are also smaller and more affordable than most of the international coral reef conferences, and intentionally designed to cross academic hierarchies-with a high proportion of early career presenters and attendees. For example, $52 \%$ and $45 \%$ of attendees at RCUK in 2016 and 2015, respectively, were students. Additionally, for undergraduate and Master's students, RCUK is frequently their first experience attending or presenting at a conference. From 2015 onwards, RCUK has awarded prizes for the best student talk and poster presentations (Andradi-Brown et al., 2016a). RCUK presentations have been given by many students or early career conservationists who have gone on to become prominent and influential at the national or international level in academia, conservation organisations, or science communication. The original RCUK committee were all early career scientists and conservationists, including several Ph.D. students, with the majority still actively engaged in coral reefs today. While the meeting has expanded and committee members have invariably changed, RCUK continues to be led by a group of early career scientists and conservationists. RCUK has remained "dedicated to the conservation and awareness of coral reefs" (RCUK, 1998) over the past two decades-as envisaged when founded.

\section{SUSTAINABLE AND INCLUSIVE CONFERENCING AT RCUK AND ECRS}

ECRS was a chance to highlight the RCUK committee's values to the European and global coral reef community. Although predominantly a UK-based network, we seek for RCUK to have global relevance. When planning and hosting ECRS and our annual RCUK conference, we strive for them to be diverse, inclusive, and as environmentally sustainable as possible. Below are some steps we have taken on the journey toward this goal.

\section{Diversity and Inclusion}

We interpret diversity and inclusion in its broadest sense, with the aim of ensuring all potential attendees feel welcome and have equal access to the conference. Many of the actions we have taken and summarise below have previously been highlighted by researchers and are also being taken up by other conferences in conservation science (e.g., Sardelis et al., 2017; Smith et al., 2017) and by other organising societies (e.g., the Equity and Diversity Committee of the American Elasmobranch Society and the Marine Section Diversity Committee of the Society for Conservation Biology). Such approaches are also being formalised as codes of conduct (e.g., Favaro et al., 2016).

To reduce conscious and unconscious bias, we have conducted blind abstract reviews since 2015 at all RCUK 
conferences. All submitted abstracts are initially reviewed and ranked blind to author names, institutions, and career stage. A minimum of five people review each abstract. Following review, we unblind all abstracts and have an open committee discussion to ensure that we accept the top ranked abstracts, but also ensure balance between institutions, types of institutions (university, non-governmental organisations, museums, aquariums, government, etc.), career stage of presenters (especially providing opportunities for students to present), gender, and geographical locations. For ECRS, we instigated a similar selection process, blinding the submitted abstracts before sending them to the symposium session organisers for initial review, and encouraging them to consider many of the issues above when making refinements to their sessions.

In terms of gender balance, $38 \%$ of presentations at RCUK between 1998 and 2016 had a woman as presenting author (Figure 1). However, as would be expected with a small conference, the percentage is highly variable year-to-year. There have been four occasions from 1998 to 2016 where the percentage of women as presenting author has been over $50 \%$. Our analysis suggests that RCUK, and likely UK reef science more generally, still requires progress to address gender balance. While we do not have data available, we are aware there is a need for RCUK, as there is for marine science in general (e.g., Mauleón et al., 2013; Smith et al., 2017), to also improve representation of a broader range of ethnic groups and wider socio-economic backgrounds.

We introduced plenary speakers to RCUK meetings for the first time in 2015 (Andradi-Brown et al., 2016a), with these talks allocated more time than standard presentations. Prior to invitations being issued, the committee discussed using the plenary speaker presentations as a platform to showcase interesting and progressive reef science and conservation in more detail than is possible in shorter format talks, while also reflecting the same balance that we want in presenters. We were particularly

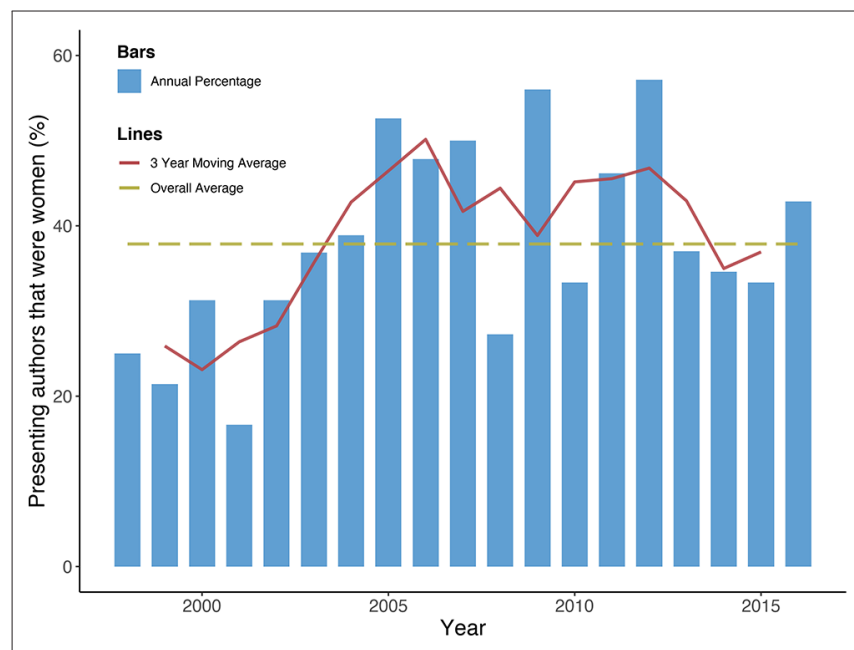

FIGURE 1 | Percentage of talks presented by women at RCUK conferences by year. The red line shows a three-year moving average (an average across the current year, the year prior, and the year following), while the green dashed line represents the mean percentage across the timeseries (38\%). keen to increase the number of women invited to give plenary talks, as this increases the visibility of women in coral reef science and can provide role models for early career women and students (Jones et al., 2014; Sardelis and Drew, 2016). From 2015 to 2017 (including ECRS) our plenary speakers included four women and two men. We also acknowledge that inequity applies to nonbinary gender identities, those with disabilities, and other aspects of intersectional diversity, and are working to identify ways to address this moving forward to further increase inclusivity and diversity.

RCUK was formed in the recognition that there was a considerable community of reef scientists and conservationists at UK institutions that would benefit from improved networking and coordination. As such, RCUK does not aim to be fully representative of global coral reef nations. We recognise, however, that bringing in more geographical representation is crucial to broaden perspectives - as the majority of tropical coral reefs are located far away from Europe. Since 2018, RCUK has fully funded a plenary speaker each year from a low- or lower-middle-income country that contains coral reefs. Our intention has been to hear about reef conservation projects from their home country, with a view to a shared learning between these applied reef conservation scientists or practitioners and UK-based researchers. We maximise the value of the trip for the speaker by providing financial support for a short placement with a UK-based conservation or academic partner relevant to their work, expanding on this shared learning. There are also many students from coral reef nations who study in the UK, and RCUK represents a valuable capacity-building and networking opportunity for them. We continue to seek opportunities to increase engagement and shared learning between the RCUK network and scientists and practitioners from tropical coral reef nations.

To increase financial accessibility of RCUK conferences and ECRS, we intentionally keep costs down and provide student travel grants. RCUK conferences are typically held at ZSL, as considerable administrative and in-kind support is provided. Furthermore, the use of ZSL facilities allows us to minimise costs. The first conference in 1998 charged a standard registration fee of $£ 25$, which had increased to $£ 40$ by 2016 - though with an additional discount for students. We believe this represents excellent value for a full day conference that includes lunch, tea and coffee, and drinks and snacks at an evening networking reception surrounded by the coral reef exhibits in the ZSL Aquarium. For ECRS, we partnered with the University of Oxford to use university-owned conference facilities. These were substantially cheaper than professional conference centres, which allowed us to pass on savings directly to our attendees through reduced registration fees. RCUK also provides travel grants to students and recent graduates. These grants are intentionally not restricted on the basis of either age or country, but instead based on career stage. ECRS travel grants were supported by ICRS. During ECRS, free professional childcare was provided within the conference building, as childcare barriers are often prohibitive for parents to attend conferences (Sardelis et al., 2017). 


\section{Environmental Sustainability}

As a coral reef science- and conservation-focused committee it is crucial we evaluate our environmental impact and maximise the sustainability of our conferences. At ECRS, we carbon offset all conference activities and all committee and plenary speaker travel required for planning and attendance. This commitment meant quantifying the venue's electricity usage during the conference and hosting the World Land Trust within the conference venue for delegates to join us in offsetting their conference travel. We avoided single-use plastic by providing water fountains around the venue and encouraging delegates to bring reusable water bottles. Paper drinking cones were provided on-request for anyone who did not have a reusable water bottle. No singleuse plates, cutlery, or cups were used in serving catered food or drinks during lunches and coffee breaks, and delegates were provided with reusable bamboo coffee cups within their plasticfree conference bags. Name badges and lanyards for conference delegates also avoided plastic, instead using laser-cut, locallysourced, wooden name badges and bamboo fibre lanyards. These have the advantage of being more durable than paper name badges without needing to be held in a plastic pouch, which was essential for a multi-day conference. The lanyards have also been used again for subsequent RCUK events. Our conference volunteer t-shirts were made from recycled plastic bottles and offcuts from the organic cotton trade and were ethically certified by Fair Wear. ECRS also strived to be a paper-free conference. The programme, schedule, and abstract book were provided through a free mobile phone application, or electronic document available on the ECRS website.

With ECRS catering for more than 550 people over three days, it was important to consider the environmental impact of the food we served. The conference was therefore fully vegetarian and used as much locally-produced food as possible-the first ICRS-sponsored event that has done this. We have continued this trend at annual RCUK meetings and are delighted that the 2021 International Coral Reef Symposium has followed our example and made their upcoming meeting fully vegetarian.

\section{CHANGING PRIORITIES OF REEF SCIENCE AND CONSERVATION}

RCUK was founded at a time when the drivers of global reef loss were still poorly recognised beyond the coral reef community, and most conservation attention was on local or regional threats. The International Coral Reef Initiative (ICRI) - a partnership between governments and other organisations to protect coral reefs (Dight and Scherl, 1997)-listed four key activities in its framework for action in 1995: (i) integrated management, (ii) capacity building, (iii) research and monitoring, and (iv) review/evidence synthesis (ICRI, 1995). Following a series of workshops, ICRI identified overfishing and pollution from sewage as the two main global threats to reefs, alongside destructive fishing and sedimentation as a consequence of poor land-use practices as additional inter-regional threats (Dight and Scherl, 1997). Indeed, widespread recognition of the effects of climate change on reefs was not apparent until the global mass coral bleaching event and mortality in 1998 (Wilkinson, 2000). For example, in the Status of Coral Reefs of the World: 2000, Wilkinson (2000) wrote: "Many coral reef scientists and resource managers were considerably shocked and depressed during 1998 when there was massive coral bleaching and mortality of corals over large reef areas in many parts of the world. This caused a major paradigm shift in concepts about the degradation of coral reefs and mechanisms for management." Since then, the role of climate change as a major global driver of coral reef degradation and loss has become well-established. For example, a Royal Society meeting produced a climate change and coral reef statement in 2009 ("The coral reef crisis: The critical importance of $<350 \mathrm{ppm} \mathrm{CO}_{2}$ "; Veron et al., 2009), and ICRS issued a consensus statement in 2015 summarising the evidence base ("Climate Change Threatens the Survival of Coral Reefs"; Hoegh-Guldberg et al., 2015). Climate change was also explicitly mentioned throughout the 2018 third IYOR recommendation adopted by ICRI (ICRI, 2016). While reducing global carbon emissions is accepted as essential to support coral reef survival into the 21 st century, there is much debate about the role of different local- and regional-level management interventions. This has led to recent advocacy efforts to avoid portraying an exclusively "doom and gloom" picture of the future of coral reefs (Abelson, 2020), and to instead promote ocean optimism (Knowlton, 2018). This can be achieved, for example, by highlighting appropriate management interventions (e.g., proper sewage treatment, effective fisheries management) that local decision-makers can take to enhance reef resilience and support reef conservation (Abelson, 2020). It is crucial to remember that reef stressors that can be addressed by localor regional-scale management are still causing widespread reef loss in many locations globally (e.g., Häder et al., 2020). Many members of the RCUK network have played important roles in advancing coral reef conservation throughout these past two decades, through science, field conservation, capacity building, or policy.

Since 1998, many of these trends in broader reef science have been reflected in presentations at the RCUK annual meeting (Figure 2). Each year, when selecting abstracts for inclusion at the conference, the RCUK committee tries to select a balance across relevant disciplines, as well as representation of career levels and institutions. Therefore, the presentations selected each year can be considered a broad proxy for general reef science and conservation priorities at the time, with a bias toward work conducted by UK-based institutions. Across the 402 abstracts accepted for talks at the conference from 1998 to 2016, we counted the number of abstracts that included key words associated with reef threats and management or conservation interventions (Table 1).

Approximately two thirds (66\%) of abstracts at RCUK conferences made reference to a "reef threat". Many of the threats identified by ICRI and IYOR are highlighted in the research presented (Figure 2A). Climate change was the single greatest reef threat presented at RCUK-included in $34 \%$ of abstracts. This was followed by fisheries-related issues (25\%) and then sedimentation (12\%). Disease and pollution were both mentioned in $9 \%$ of abstracts. Noteworthy is the fact that disease 
A

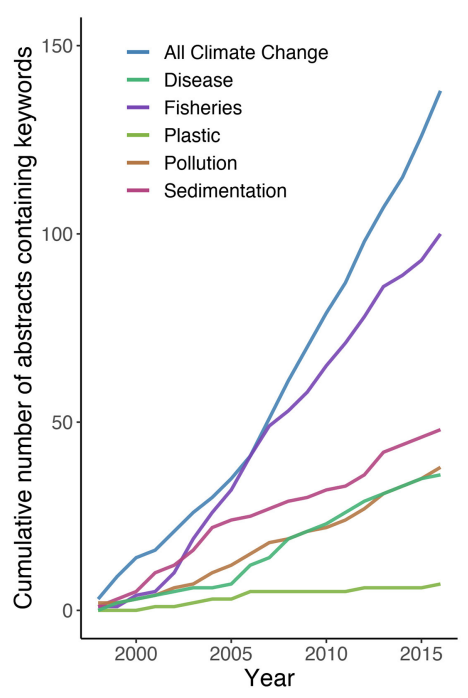

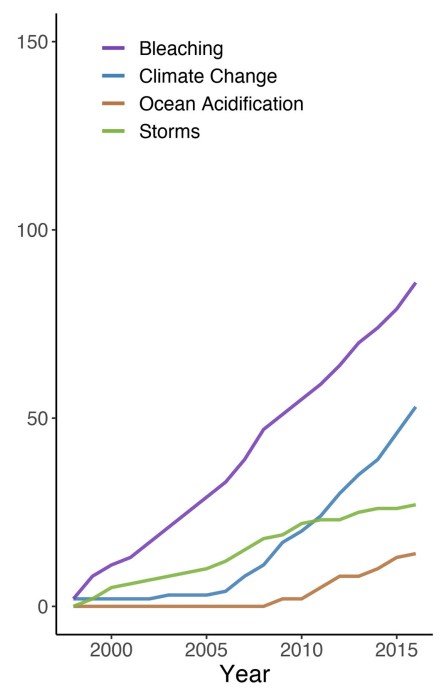

C

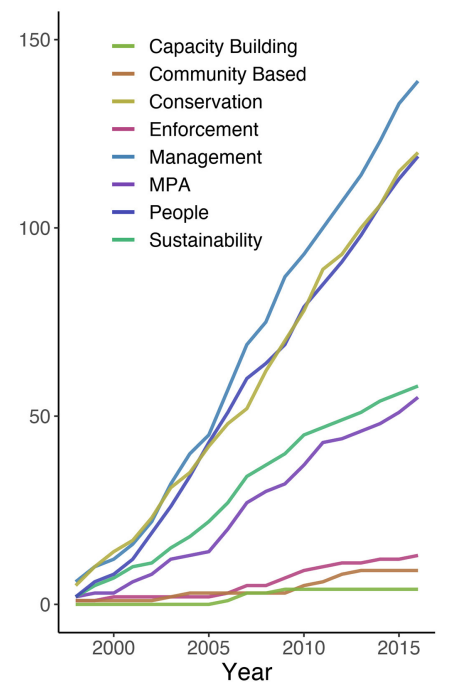

FIGURE 2 | Cumulative trends in the number of abstracts on key topics at RCUK from 1998 to 2016. Trends shown for (A) reef threats, (B) climate change related impacts, and (C) conservation and management actions. Results show the cumulative number of talk abstracts through time based on keyword analysis on the abstract contents (see Table 1 for keywords included in each topic).

received little attention prior to 2005 (Figure 2A). The increased prominence of coral disease is likely associated with the increased profile of diseases emerging as a major scleractinian coral threat (Harvell et al., 1999; Sweet et al., 2012). Plastic pollution, despite a recent high profile (Villarrubia-Gómez et al., 2018; Stafford and Jones, 2019), has featured the least of all reef threats.

The most common climate change-related impact mentioned in $21 \%$ of RCUK presentations has been coral bleaching (Figure 2B). Unsurprisingly, as the first RCUK conference occurred in November 1998-toward the end of the first reported global mass coral bleaching event (Wilkinson, 2000) presentations discussed preliminary results of the impact of bleaching on coral reefs. These first conference presentation titles included phrases such as "catastrophic coral bleaching" and "can coral adapt to climate change" (RCUK, 1998). More presentations refer to bleaching than climate change throughout the time series (Figure 2B), likely reflecting the fact that bleaching is a sign of coral stress directly observable by researchers and can also be caused by non-climate change related processes, e.g., disease. Presentations related to bleaching were a mainstay of meetings from 1998 to 2016, while climate change became much more prominent after 2006 (Figure 2B). Whilst storm impacts and ocean acidification were mentioned in 7 and 3\% of abstracts, respectively, presentations relating to ocean acidification were completely absent prior to 2008 (Figure 2B).

From 1998 to 2016, over half (59\%) of abstracts included reference to conservation or management. Given that the original aim of RCUK included "promoting conservation...about coral reefs" and "ensuring that all reef related activities are conducted in a responsible manner", it is encouraging to see a high number of abstracts either directly studying these issues or relating research to potential applied impact. Management issues (comprised of keywords "management", "management capacity", and "effectiveness") were the most commonly mentioned termspresent in 35\% of abstracts (Figure 2C), followed by conservation and people (both $30 \%$ of accepted abstracts). Sustainability and Marine Protected Areas (MPAs) were each mentioned in $14 \%$ of abstracts, with MPAs being the single biggest named conservation intervention discussed at RCUK. However, the use of community-based conservation approaches and enforcement have been noticeably lacking in past RCUK conferences (Figure 2C). Overall, there has been little change through time in the discussion of conservation and management approaches.

\section{RESEARCH TOPIC OVERVIEW}

This Research Topic "Coral Reefs in the Anthropocene" marks the 20th anniversary of RCUK, and was assembled jointly as a conference proceedings volume for ECRS and an open call via the Frontiers in Marine Science journal website for additional submissions. This Research Topic contains 20 papers involving 104 authors and covers many issues at the cutting-edge of reef science and conservation. Papers span basic and applied science, such as the diversity of coral holobionts, coral disease, nutrient impacts, recovery potential for coral reefs, and support for MPA expansions. Here, we briefly summarise each contribution and highlight their importance to the study of coral reefs.

Coral reefs are built by stony corals that comprise metaorganisms, or so-called holobionts (Rohwer et al., 2002). For decades, the association between coral animals and their intracellular microalgal partners in the family Symbiodiniaceae has been the subject of intense research given that this symbiosis comprises the foundation of reef ecosystems (LaJeunesse et al., 2018). However, more recently, the role of bacteria in helping 
TABLE 1 | Keywords used to identify changes in frequency of different topics presented.

\begin{tabular}{|c|c|c|}
\hline Category & Group & Keywords \\
\hline \multirow[t]{6}{*}{ Reef Threats } & Fisheries & Fishing; Fisheries \\
\hline & Sedimentation & Sedimentation; Sediment \\
\hline & Pollution & Pollution; Nutrient; Waste \\
\hline & Plastic & Plastic \\
\hline & Disease & Disease \\
\hline & All climate change & $\begin{array}{l}\text { Climate change; Bleaching; Global } \\
\text { warming; Bleaching; Ocean acidification; } \\
\text { Cyclone; Hurricane; Typhoon; Storm; Sea } \\
\text { Surface Temperature; SST }\end{array}$ \\
\hline \multirow[t]{4}{*}{ Climate change } & Climate change & Climate change; Global warming \\
\hline & Bleaching & Bleaching; Sea surface temperature; SST \\
\hline & Ocean acidification & Ocean acidification \\
\hline & Storms & Cyclone; Hurricane; Typhoon; Storm \\
\hline \multirow{8}{*}{$\begin{array}{l}\text { Conservation and } \\
\text { management }\end{array}$} & Management & $\begin{array}{l}\text { Management; Management capacity; } \\
\text { Effectiveness }\end{array}$ \\
\hline & MPA & $\begin{array}{l}\text { Marine protected area; Marine reserve; } \\
\text { MPA; Zoning }\end{array}$ \\
\hline & Enforcement & Enforcement; Patrol \\
\hline & Community based & Community based; Community-based \\
\hline & Sustainability & Sustainab \\
\hline & Capacity building & Capacity building \\
\hline & People & $\begin{array}{l}\text { Resource use; People; Human; Fisher; } \\
\text { Well-being; Well-being; Social }\end{array}$ \\
\hline & Conservation & Conservation \\
\hline
\end{tabular}

All talk abstracts $(n=402)$ presented at RCUK from 1998 to 2016 were analysed. The number of abstracts containing keywords associated with one or more of groups were identified for each year. Searches for keywords were not case-sensitive. Categories and groups align with Figure 2.

corals remain healthy and resilient has been acknowledged (Reshef et al., 2006; Bourne et al., 2016; Ziegler et al., 2017), but few studies investigated how they interact with other holobiont compartments (Robbins et al., 2019). In this Research Topic, several papers studied the coral holobiont to document microbial taxa present and how these differed between locations in the coral polyp or between different scleractinian coral species. For example, Engelen et al. looked at microbial communities associated with the surface mucus, tissue, and gastrovascular cavity of two azooxanthellate Caribbean cup corals. They found high similarity between microbial communities in both species in the surface mucus and tissue, but not in the gastrovascular cavity. Weiler et al. looked at bacterial communities associated with coral tissue and mucus in a deep-sea cold-water coral and found that many of these are likely to be involved in nitrogen cycling. Finally, van de Water et al. studied how seasonal environmental conditions, specifically changes in ultraviolet radiation, affected coral holobiont composition and coral functioning in Acropora muricata. Despite finding seasonal effects on the coral holobiont, they found little evidence that ultraviolet radiation was driving this. However, they found large seasonal effects on coral processes such as photosynthesis and calcification. Collectively, these studies demonstrate how much there is to learn about the microbiome, including the taxonomic diversity, their functional importance, and variation across temporal and biophysical gradients. While it is clear that a better understanding of the microbiome will be critical for understanding the impact of stressors on corals in the Anthropocene, these studies highlight the difficulty in predicting the response of corals under future scenarios of climate change.

A further benefit of understanding the microbiome is a better understanding of the causes of coral disease. Disease is a major threat to corals-particularly in places with high local anthropogenic impacts (Sweet and Brown, 2016), and was a key theme presented at ECRS. Three studies considered the effects of disease on either individual corals or on the reef systems as a whole. Rivera-Ortega and Thomé studied the properties of the surface mucus from three cnidarians, including a scleractinian coral and an anemone, finding that this had antibacterial properties. They also found corals with black band disease had diminished antibacterial capacity in the mucus layer. Walton et al. looked at the regional impact of an outbreak of white syndrome disease in Florida in 2014. The disease affected multiple coral species and led to a $30 \%$ loss of scleractinian coral density, and, in many cases, over $60 \%$ tissue loss from individual colonies. Also in Florida, Goergen et al. conducted a long-term study from 2008 to 2016 on two large Acropora cervicornis patches (each over 1 ha in extent). They found a range of factors that led to a $>50 \%$ loss of $A$. cervicornis over the 8 -years periodincluding diseases such as rapid tissue loss and white band disease, alongside storms and elevated sea surface temperatures. Overall, their conclusion was that the recovery time between disturbance events was not sufficient for this keystone Caribbean coral to recover and regrow. These papers show the importance of disease as a driver of declining coral cover, particularly when combined with other stressors, but also how little we know about their causes and epidemiology. Diseases, combined with storms and elevated SST can prevent keystone coral species from reestablishing, ultimately preventing reefs from recovering and regrowing. The recent coral mortality from stony coral tissue loss disease in the Caribbean (e.g., Precht et al., 2016) further reminds us of how important filling these research gaps will be in the Anthropocene, and how mitigating local stressors is still critical while simultaneously addressing global climate change.

While local stressors significantly impact some reefs, climate change clearly affects reefs throughout the world (Eakin et al., 2019). Elevated thermal stress is well-known to cause scleractinian coral bleaching, which can eventually lead to coral mortality if prolonged (Wilkinson, 2000; Hughes et al., 2017). However, less is known about sub-lethal effects of warming. Palmer considered the activity of key coral immune pathways and an antioxidant in response to coral tissue damage. When uninjured corals were exposed to warmer water (below the temperatures that induced bleaching) the background rate of production of immunity and antioxidant enzymes increased. At higher temperatures, however, the immune responses to tissue damage were significantly delayed. Considering coral bleaching, Wang et al. conducted a field experiment on Agaricia sp. colonies to investigate how elevated nitrogen and phosphorous levels affected bleaching and mortality. They found nitrogen in isolation prolonged bleaching and increased mortality. They 
also found high prevalence of dark spot syndrome, but nutrient exposure did not increase the prevalence or severity of this disease. In a related study, Poquita- $\mathrm{Du}$ et al. tested how increased water temperature and sediment exposure affected gene expression in Pocillopora acuta. Whilst their results showed that sediment had little effect on gene expression, the combined treatments of elevated temperature and sediment resulted in a synergistic effect, with greater gene expression changes than would be predicted from the effects of either heat or sediment alone, including declines in symbiont density. It is clear that climate change will exert a major influence on all ecosystems, including coral reefs, during the Anthropocene. While coral bleaching is typically the focal impact of increasing sea surface temperatures, these papers demonstrate the need to also consider sub-lethal impacts, and this will be aided by new approaches such as epigenetics (Eirin-Lopez and Putnam, 2019). Poquita-Du et al. is also a timely reminder of the need to consider synergistic effects among reef stressors (Darling and Côté, 2008).

As coral reefs are highly diverse complex ecosystems, there are many different forms of ecological interactions occurring between species, and interactions between species and their abiotic environment. Rice et al. provided a review of corallivory-the predation of corals. Corallivory is an important feeding pathway for many reef organisms. This review, however, paints an unsettling picture of global corallivory, climate change, and local reef stressors potentially interacting to drive large-scale change on reefs. Our second ecological interaction study considered algal-coral-herbivore interactions on heavily impacted reefs in Singapore. Leong et al. found that the presence of macroalgae reduced coral settlement rate, while the loss of herbivores led to lower juvenile coral survival and increased sediment build up. Their results highlight the importance of interactions between species for maintaining healthy reef ecosystems. Bucher and Harrison studied the effects of elevated nutrient levels on growth rates of Acropora longicyathus and found that increased phosphate levels caused faster tissue growth rates and increased apical calcification. Phosphate exposure, however, also reduced coral surface mucus. Reduced mucus may reduce coral survival in polluted waters because of the important role it has in removing sediment from coral surfaces and in preventing disease. Bucher and Harrison also found corals exposed to higher nitrogen levels had reduced growth rates and reduced ability to heal tissue damage. In another paper in this Research Topic, Piñón-González and Banaszak investigated the effects of partial colony mortality on Acropora palmata in the Mexican Caribbean. They found there was no difference in growth rates between colonies that had experienced partial mortality versus those that had not. However, areas of the colony that had suffered mortality did not recover, and these colonies then also had decreased egg quality during reproduction. Studies such as these indicate that coral recovery is not straightforward, and under climate change conditions could be compromised even further. There has been significant progress on understanding the resilience of coral reefs (e.g., Mumby et al., 2007), and predicting the recovery of reefs after increasingly frequent disturbances in the Anthropocene will be critical. Better parameterisation of ecological processes and abiotic interactions are key for improving the model of reef benthic dynamics.

Understanding scleractinian coral reproductive patterns is crucial for effective reef restoration efforts. Yet much of the current global coral reef research effort does not align with the locations with the greatest coral reef threats or species richness (Fisher et al., 2011). In the Karimunjawa Archipelago, Indonesia, Wijayanti et al. investigated reproductive seasonality of 21 Acropora species over 5 years. They report that Acropora spp. exhibit a high degree of seasonality in their reproductive cycle and suggest that there could be some synchronicity in spawning in the region. Building on our inherent understanding of coral spawning in the Great Barrier Reef, Chan et al. hybridised two Acropora species pairs to investigate hybrid responses to elevated temperature and carbon dioxide. While hybrid responses were variable, some individuals exhibited greater survival under elevated temperature and carbon dioxide than the parental species. While much work is still required, these results support a growing evidence base that hybridisation can enhance climate resilience for scleractinian corals and hybrid production could become an important tool in coral restoration efforts.

Several papers in this Research Topic explored poorly-studied reef systems and include calls for urgent management-from MPA implementation to preventing oil and gas extraction. These papers contain highly valuable information for those at the front lines of conservation and have the potential to influence marine management decision-makers, alongside highlighting crucial knowledge gaps on neglected, human-influenced systems. First, Francini-Filho et al. provided an overview of the Great Amazon Reef system. While the existence of a reef system adjacent to the mouth of the Amazon River has been known to researchers since the 1970s (Collette and Rützler, 1977), it has been very poorly documented. In their paper Francini-Filho et al. report the first video surveys conducted that captured the structure of this system. Their paper shows that the reef system is likely larger than previously thought-extending both further along the coast and deeper-while also having greater habitat complexity and diversity than previously recorded. The authors also warn of the increasing threat to the reef from oil and gas extraction in the region, and call for a network of MPAs to be established to protect the Amazon reef. Their paper captured global attention, and currently is the most viewed article ever published by Frontiers in Marine Science.

This Research Topic also contained two complimentary papers from Garavelli et al. and Studivan and Voss investigating connectivity between mesophotic coral ecosystems (reefs from 30 to $150 \mathrm{~m}$ depth) in the Northwest Gulf of Mexico. Both of these papers were framed in response to proposals to expand the Flower Garden Banks National Marine Sanctuary with the potential to afford coral reef habitats in the Northwest Gulf of Mexico increased protection. While mesophotic coral ecosystems are historically poorly studied globally (Bridge et al., 2013), this has rapidly changed in recent years (Turner et al., 2017; Laverick et al., 2018), and there is now evidence they can be heavily impacted by anthropogenic activities (Andradi-Brown et al., 2016b). Garavelli et al. used larval dispersal modelling and 
highlighted the high potential for scleractinian coral connectivity between all mesophotic offshore banks and also shallow reefs in the region. Studivan and Voss used molecular ecology methods to show high population connectivity for Montastraea cavernosa across the Northwest Gulf of Mexico. Taken together, these papers reach the conclusion that coral populations living in the region should be managed as a single unit, and advocate for the expansion of the national marine sanctuary. Finally, Gorospe et al. were interested in how reef fish recovery potential might inform marine spatial planning or MPA implementation. The authors constructed a series of Bayesian models to investigate the capacity for Hawaiian reefs to support fish biomass and compared these results to contemporary biomass levels. Their analysis showed surprising variation in the natural capacity for reefs to support herbivorous fish biomass and overall fish biomass, as well as the significant negative effect human population density has on fish biomass throughout Hawaii. As we move through the Anthropocene, inevitably research and conservation efforts will focus on well-studied shallow-water reefs, but this work reminds us of the need to continually search for and protect poorly documented reefal areas and consider potential conservation outcomes from protection.

The final paper in our Research Topic, by Chabanet et al. evaluated the impact of a coral reef education project in New Caledonia. The authors provide details of a fun and actionorientated toolbox of activities, including picture books, card games, and board games, for awareness-raising with children aged 5-11 years old titled: "The Coral Reef in Our Hands." Students who went through this education activity had greater knowledge of reef biodiversity and awareness of connections between coral reefs and the wider environment.

It is axiomatic that coral reefs and the ecosystem services they provide are threatened by a wide range of stressors. While we can optimistically hope that some stressors can be mitigated, there is an increasing recognition that reefs in the Anthropocene will function differently and need managing accordingly (Rogers et al., 2015; Hughes et al., 2017; Bellwood et al., 2019). The basis of this new future will be a combination of science and conservation, international and interdisciplinary collaboration, and communication and outreach to the public and a wide range of stakeholders. Conferences such as RCUK aim to facilitate these efforts, and the papers included in this Research Topic demonstrate their value. Spanning topics from coral microbiomes to mesophotic reefs, the papers demonstrate the effects of a variety of stressors to corals and coral reefs-and

\section{REFERENCES}

Abelson, A. (2020). Are we sacrificing the future of coral reefs on the altar of the "climate change" narrative? ICES J. Mar. Sci. 77, 40-45 doi: 10.1093/icesjms/fsz226

Andradi-Brown, D. (2015). 17th Annual Reef Conservation UK (RCUK) Meeting. Reef Encounter 41, 55-56.

Andradi-Brown, D., Laverick, J., Bejarano, I., Bridge, T., Colin, P., Eyal, G., et al. (2016b). "Threats to mesophotic coral ecosystems and management options," in Mesophotic Coral Ecosystems - A Lifeboat for Coral Reefs? once again underscore how little we currently know but also the urgency of more research and effective conservation to lead to better outcomes for people and nature.

\section{RCUK INTO THE FUTURE}

We continue to look for new ways to keep RCUK conferences fresh and engaging for the reef community we support. We are delighted that this Research Topic won the 2019 Frontiers Spotlight Award, as this will provide much needed funding and support to host a series of workshops on applied conservation science that will address the major issues facing coral reefs. We plan to invite the world's leading coral reef scientists, conservationists, and policy experts to produce several highimpact papers and policy briefs to chart the way forward for reefs in our rapidly changing world. We will be bringing our RCUK values to this event, with the resources provided by the Frontiers Spotlight Award providing an opportunity to progress our approaches to environmental sustainability, diversity, and inclusion.

Reflecting on the past 20 years of RCUK activities including ECRS, as a UK reef network and annual conference we feel that we have met and even exceeded the expectations of the original 1998 RCUK vision, while also continuing to progress and improve the mechanisms by which we deliver it. We will continue to build RCUK activities in the future and remain "dedicated to the conservation and awareness of coral reefs" (RCUK, 1998).

\section{AUTHOR CONTRIBUTIONS}

DC and DA-B conducted the analysis. DA-B wrote the first draft of the manuscript. All authors contributed to manuscript revision, read, and approved the submitted version.

\section{ACKNOWLEDGEMENTS}

We thank ZSL for continued long-term support to RCUK. We also wish to thank ZSL, University of Oxford, and the International Coral Reef Society for support with ECRS. The RCUK committee expresses our heartfelt thanks to all coral reef enthusiasts who have participated in, volunteered at, or helped build the RCUK network and annual meetings since 1998. This is contribution \#189 from the Coastlines and Oceans Division in the Institute for Environment at Florida International University.

eds E. K. Baker, K. A. Puglise, and P. T. Harris (Nairobi and Arendal: The United Nations Environment Programme and GRID-Arendal), $67-82$.

Andradi-Brown, D., Yalett, R., and Richards, K. (2016a). 18th Annual Reef Conservation UK (RCUK) Meeting. Reef Encounter 43:67.

Bellwood, D. R., Pratchett, M. S., Morrison, T. H., Gurney, G. G., Hughes, T. P., Álvarez-Romero, J. G., et al. (2019). Coral reef conservation in the Anthropocene: Confronting spatial mismatches and prioritizing functions. Biol. Conserv. 236, 604-615. doi: 10.1016/j.biocon.2019. 05.056 
Bourne, D. G., Morrow, K. M., and Webster, N. S. (2016). Insights into the coral microbiome: underpinning the health and resilience of reef ecosystems. Annu. Rev. Microbiol. 70, 317-340. doi: 10.1146/annurev-micro-102215-0 95440

Bridge, T. C. L., Hughes, T. P., Guinotte, J. M., and Bongaerts, P. (2013). Call to protect all coral reefs. Nat. Clim. Chang 3, 528-530. doi: 10.1038/ nclimate 1879

Collette, B. B., and Rützler, K. (1977). "Reef fishes over sponge bottoms off the mouth of the Amazon River," in Proceedings of the Third International Coral Reef Symposium (Miami, FL: Florida University of Miami), 305-310.

Darling, E. S., and Côté, I. M. (2008). Quantifying the evidence for ecological synergies. Ecol. Lett. 11, 1278-1286. doi: 10.1111/j.1461-0248.2008.0 1243.x

Dight, I. J., and Scherl, L. M. (1997). The International Coral Reef Initiative (ICRI): Global priorities for the conservation and management of coral reefs and the need for partnerships. Coral Reefs 16, S139-S147. doi: 10.1007/s0033800 50250

Eakin, C. M., Sweatman, H. P. A., and Brainard, R. E. (2019). The 2014-2017 global-scale coral bleaching event: insights and impacts. Coral Reefs 38, 539-545. doi: 10.1007/s00338-019-0 1844-2

Eirin-Lopez, J. M., and Putnam, H. M. (2019). Marine Environmental Epigenetics. Ann. Rev. Mar. Sci. 11, 335-368. doi: 10.1146/annurev-marine-010318-095114

Favaro, B., Oester, S., Cigliano, J. A., Cornick, L. A., Hind, E. J., Parsons, E. C. M., et al. (2016). Your science conference should have a code of conduct. Front. Mar. Sci. 3:103. doi: 10.3389/fmars.2016.00103

Fisher, R., Radford, B. T., Knowlton, N., Brainard, R. E., Michaelis, F. B., and Caley, M. J. (2011). Global mismatch between research effort and conservation needs of tropical coral reefs. Conserv. Lett. 4, 64-72. doi: 10.1111/j.1755-263X.2010.00146.x

Häder, D.-P., Banaszak, A. T., Villafañe, V. E., Narvarte, M. A., González, R. A., and Helbling, E. W. (2020). Anthropogenic pollution of aquatic ecosystems: emerging problems with global implications. Sci. Total Environ. 713:136586. doi: 10.1016/j.scitotenv.2020.136586

Harvell, C. D., Kim, K., Burkholder, J. M., Colwell, R. R., Epstein, P. R., Grimes, D. J., et al. (1999). Emerging marine diseases-climate links and anthropogenic factors. Science 285, 1505-1510. doi: 10.1126/science.285.5433.1505

Hicks, C. C., and Cinner, J. E. (2014). Social, institutional, and knowledge mechanisms mediate diverse ecosystem service benefits from coral reefs. Proc. Natl. Acad. Sci. U.S.A. 111, 17791-17796. doi: 10.1073/pnas.1413473111

Hoegh-Guldberg, O., Eakin, C. M., Hodgson, G., Sale, P. F., and Veron, J. E. N. (2015). "International Society for Reef Studies consensus statement on climate change and coral bleaching. Climate change threatens the survival of coral reefs," in Prepared for the 21st Session of the Conference of the Parties to the United Nations Framework Convention on Climate Change (Paris).

Hughes, T. P., Barnes, M. L., Bellwood, D. R., Cinner, J. E., Cumming, G. S., Jackson, J. B. C., et al. (2017). Coral reefs in the Anthropocene. Nature 546, 82-90. doi: 10.1038/nature22901

ICRI (1995). "International Coral Reef Initiative Framework for Action," in 1st International Coral Reef Initiative General Meeting, Silliman University (Dumaguete City, The Philippines).

ICRI (2016). "Recommendation designating 2018 as the third International Year of the Reef," in 31st International Coral Reef Initiative General Meeting (Paris, France).

Jones, T. M., Fanson, K. V., Lanfear, R., Symonds, M. R. E., and Higgie, M. (2014). Gender differences in conference presentations: a consequence of self-selection? PeerJ 2:e627. doi: 10.7717/peerj.627

Knowlton, N. (2018). Earth Optimism-recapturing the positive. Oryx 53, 1-2. doi: 10.1017/S0030605318001333

LaJeunesse, T. C., Parkinson, J. E., Gabrielson, P. W., Jeong, H. J., Reimer, J. D., Voolstra, C. R., et al. (2018). Systematic revision of Symbiodiniaceae highlights the antiquity and diversity of coral endosymbionts. Curr. Biol. 28, 2570-2580.e6. doi: 10.1016/j.cub.2018.07.008

Lau, J. D., Hicks, C. C., Gurney, G. G., and Cinner, J. E. (2019). What matters to whom and why? Understanding the importance of coastal ecosystem services in developing coastal communities. Ecosyst. Serv. 35, 219-230. doi: 10.1016/j.ecoser.2018.12.012
Laverick, J. H., Piango, S., Andradi-Brown, D. A., Exton, D. A., Bongaerts, P., Bridge, T. C. L., et al. (2018). To what extent do mesophotic coral ecosystems and shallow reefs share species of conservation interest? A systematic review. Environ. Evid. 7:15. doi: 10.1186/s13750-018-0127-1

Lewis, S. L., and Maslin, M. A. (2015). Defining the Anthropocene. Nature 519, 171-180. doi: 10.1038/nature14258

Mauleón, E., Hillán, L., Moreno, L., Gómez, I., and Bordons, M. (2013). Assessing gender balance among journal authors and editorial board members. Scientometrics 95, 87-114. doi: 10.1007/s11192-012-0824-4

Mumby, P. J., Hastings, A., and Edwards, H. J. (2007). Thresholds and the resilience of Caribbean coral reefs. Nature 450, 98-101 doi: 10.1038/nature 06252

Pandolfi, J. M., Bradbury, R. H., Sala, E., Hughes, T. P., Bjorndal, K. A., Cooke, R. G., et al. (2003). Global trajectories of the long-term decline of coral reef ecosystems. Science 301, 955-958. doi: 10.1126/science.10 85706

Precht, W. F., Gintert, B. E., Robbart, M. L., Fura, R., and van Woesik, R. (2016). Unprecedented disease-related coral mortality in southeastern Florida. Sci. Rep 6:31374. doi: 10.1038/srep31374

RCUK (1998). Programme and Abstracts Reef Conservation UK Meeting 9 November 1998. London: Zoological Society of London.

Reshef, L., Koren, O., Loya, Y., Zilber-Rosenberg, I., and Rosenberg, E. (2006), The coral probiotic hypothesis. Environ. Microbiol. 8, 2068-2073. doi: 10.1111/j.1462-2920.2006.01148.x

Robbins, S. J., Singleton, C. M., Chan, C. X., Messer, L. F., Geers, A. U., Ying, H., et al. (2019). A genomic view of the reef-building coral Porites lutea and its microbial symbionts. Nat. Microbiol. 4, 2090-2100. doi: 10.1038/s41564-019-0532-4

Rogers, A., Harborne, A. R., Brown, C. J., Bozec, Y. M., Castro, C., Chollett, I., et al. (2015). Anticipative management for coral reef ecosystem services in the 21st century. Glob. Chang. Biol. 21, 504-514. doi: 10.1111/gcb. 12725

Rohwer, F., Seguritan, V., Azam, F., and Knowlton, N. (2002), Diversity and distribution of coral-associated bacteria. Mar. Ecol. Prog. Ser. 243:1-10. doi: $10.3354 /$ meps 243001

Sardelis, S., and Drew, J. A. (2016). Not "pulling up the ladder": women who organize conference symposia provide greater opportunities for women to speak at conservation conferences. PLoS ONE 11:e0160015. doi: 10.1371/journal.pone.0160015

Sardelis, S., Oester, S., and Liboiron, M. (2017). Ten strategies to reduce gender inequality at scientific conferences. Front. Mar. Sci. 4:231. doi: 10.3389/fmars.2017.00231

Smith, N. S., Côté I. M., Martinez-Estevez, L., Hind-Ozan, E. J., Quiros, A. L., Johnson, N., et al. (2017). Diversity and inclusion in conservation: a proposal for a marine diversity network. Front. Mar. Sci. 4:234. doi: 10.3389/fmars.2017.00234

Stafford, R., and Jones, P. J. S. (2019). Viewpoint-ocean plastic pollution: a convenient but distracting truth? Marine Policy 103, 187-191. doi: 10.1016/j.marpol.2019.02.003

Sweet, M., Jones, R., and Bythell, J. (2012). Coral diseases in aquaria and in nature. J. Mar. Biol. Assoc. UK. 92, 791-801. doi: 10.1017/S00253154110 01688

Sweet, M. J., and Brown, B. E. (2016). Coral responses to anthropogenic stress in the twenty- first century: an ecophysiological perspective. Oceanograp. Mar. Biol. Ann. Rev. 54, 271-314. doi: 10.1201/9781315368597

Teh, L. S. L., Teh, L. C. L., and Sumaila, U. R. (2013). A global estimate of the number of coral reef fishers. PLoS ONE 8:e65397. doi: 10.1371/journal.pone.0065397

Teleki, K., Harborne, A., Hall, H., and Wood, L. (2001). Reef Conservation UK (RCUK). Reef Encounter 30, 46-47.

Turner, J. A., Andradi-Brown, D. A., Gori, A., Bongaerts, P., Burdett, H. L., Ferrier-Pagès, C., et al. (2019). "Key questions for research and conservation of mesophotic coral ecosystems and temperate mesophotic ecosystems," in Mesophotic Coral Ecosystems Coral Reefs of the World, eds Y. Loya, K. Puglise, T. Bridge (Cham: Springer), 989-1003. doi: 10.1007/978-3-319-92735-0_52

Turner, J. A., Babcock, R. C., Hovey, R., and Kendrick, G. A. (2017). Deep thinking: a systematic review of mesophotic coral ecosystems. ICES J. Mar. Sci. 74, 2309-2320. doi: 10.1093/icesjms/fsx085 
van Hooidonk, R., Maynard, J., Tamelander, J., Gove, J., Ahmadia, G., Raymundo, L., et al. (2016). Local-scale projections of coral reef futures and implications of the Paris Agreement. Scient. Rep. 6:39666. doi: 10.1038/srep 39666

Veron, J. E. N., Hoegh-Guldberg, O., Lenton, T. M., Lough, J. M., Obura, D. O., Pearce-Kelly, P., et al. (2009). The coral reef crisis: the critical importance of $<350 \mathrm{ppm} \quad \mathrm{CO}_{2}$. Mar. Pollut. Bull. 58, 1428-1436 doi: 10.1016/j.marpolbul.2009.09.009

Villarrubia-Gómez, P., Cornell, S. E., and Fabres, J. (2018). Marine plastic pollution as a planetary boundary threat-The drifting piece in the sustainability puzzle. Mar. Policy 96, 213-220. doi: 10.1016/j.marpol.2017.11.035

Wilkinson, C. R. (2000). Status of Coral Reefs of the World: 2000. Townsville \& Dampier: Australian Institute of Marine Science.

Ziegler, M., Seneca, F. O., Yum, L. K., Palumbi, S. R., and Voolstra, C. R. (2017). Bacterial community dynamics are linked to patterns of coral heat tolerance. Nature Commun. 8:14213. doi: 10.1038/ncomms14213
Conflict of Interest: KR was, at the time of writing, employed by the company Atmosphere Resorts. EW was a freelance consultant but participated on a voluntary basis in this manuscript.

The remaining authors declare that the research was conducted in the absence of any commercial or financial relationships that could be construed as a potential conflict of interest.

Copyright (c) 2020 Andradi-Brown, Banaszak, Frazer, Gilchrist, Harborne, Head, Koldewey, Levy, Richards, Short, Sweet, Teleki, Voolstra, Wilson, Wood, Yarlett and Curnick. This is an open-access article distributed under the terms of the Creative Commons Attribution License (CC BY). The use, distribution or reproduction in other forums is permitted, provided the original author(s) and the copyright owner(s) are credited and that the original publication in this journal is cited, in accordance with accepted academic practice. No use, distribution or reproduction is permitted which does not comply with these terms. 